\title{
Investment Analysis for Largest Heavy Oil Field in Indonesia Under Indonesia's Gross-Split Production Sharing Contract (PSC)
}

\author{
Muhammad Nail Ritinov \\ Institut Teknologi Bandung \\ Ahmad Danu Prasetyo \\ Institut Teknologi Bandung
}

XYZ field is largest heavy oil field in Indonesia, located in ABC Block PSC that will be managed by a National Oil Company (NOC) under new form of PSC, the Gross-Split PSC for 20 years starting August 2021- August 2041. This research aims to assess the investment analysis of XYZ field to find the best investment alternative that will give highest financial return for NOC. Data used are mostly secondary data that author retrieve from internal and external sources. Result from strategic approach show that $A B C$ Block, especially XYZ field has a competitive advantage therefore NOC should maximize its investment in $A B C$ Block. The result of economic evaluation show that Alternative-3 (Combination Program) is best alternative due to highest NPV value.

Keywords: investment, heavy oil, Gross Split, Production Sharing Contract

\section{INTRODUCTION}

Indonesia is a well-known significant player in the international oil and gas industry. The history can be traced back to 1885 when first oil discovered in North Sumatera. Indonesia also an international pioneer in many areas of the industry, including the development of the Production Sharing Contract (PSC) - one of the types of Joint Cooperation Contract. Under a (conventional) PSC, the Government and the Contractor agree to take a split of the production, measured in terms of revenue, based on PSC-agreed percentages. Operating costs are recovered from production through Contractor cost oil formulas as defined by the PSC, and the Contractor has the right to take and separately dispose of its share of oil and gas (with title to the hydrocarbons passing at the point of export or delivery).

It may be arguable, but for many of industry players, the most critical barrier to the industry's investment is the regulatory hurdles and bureaucratic processes associated with the approval of expenditure. During last recent years, the Government also sought to reduce the overall bureaucracy with steps aimed at simplifying the current regulations and providing more clarity on key areas of uncertainty such as fiscal terms. As part of this, the Government introduced the new "Gross Split PSC" concept in early 2017.

The other problem of oil industry in Indonesia there are many of PSC blocks that will expiry within next 5 years. Ministry of Energy and Resources Mineral (MERM) identify that there are 18 PSC contract that will expire in 2021-2026. One of the expiring blocks is ABC Block, which will expiry in August 2021 and currently is the biggest contribution PSC block to the national production. 
$\mathrm{ABC}$ Block PSC (ABC), once known as the biggest crude producing block in Indonesia- as its position has overtaken by Cepu Oil block in early 2019, produces around 208,000 bopd in 2018, or about 25\% of Indonesia's total oil output. It has been operated by International Oil Company (IOC) or its related name for more than 90 years.

There are two types of oil in ABC, heavy oil and light oil. Heavy oil refers to highly-viscous oil that cannot easily flow to production wells under normal reservoir conditions. It is referred to as "heavy" because its density or specific gravity is higher than that of light crude oil. Heavy crude oil has been defined as any liquid petroleum with an API gravity less than $20^{\circ}$, while light oil is liquid petroleum that has a low density and flows freely at room temperature. It has a low viscosity, low specific gravity and high API gravity due to the presence of a high proportion of light hydrocarbon fractions. It generally has a low wax content.

Heavy oil in ABC is produced from XYZ Field (XYZ) and other small field, while light oil is produced from more than 90 field including about eight large fields.

$\mathrm{XYZ}$ is the largest heavy oil producing field in Indonesia, approximately $18 \mathrm{~km}$ long and $18 \mathrm{~km}$ wide. It is located in the South Sumatra Basin on the eastern coast of Sumatera, Indonesia. XYZ was discovered in 1941. First production was at 1954 with primary production peaked at 65,000 bpd (barrel per day) in the mid-1960s. The oil output of the field is sent to the port of Dumai via a 25" pipeline across Riau province. In late July 2018, Government of Indonesia (GOI) thru Minister of Energy and Mineral Resources (MEMR) has awarded ABC Block PSC to National Oil Company (NOC) for a 20-year period. NOC will take over operatorship when the current contract operated by IOC's subsidiary, International Oil Company (IOC), expires in August 2021. Despite the political nuance of the selection, former Deputy Energy Minister Arcandra Tahar said proposal made by IOC for an extension of its contract after 2021 was "far below" an offer made by NOC, referring to a comparison of projections of state revenue and other terms proposed by both companies.

NOC offered a "better proposal" for the operation of ABC Block in Riau Province -- including a \$784 million signature bonus and a $\$ 500$ million exploitation commitment. While for Capital Expenditure (Capex), NOC estimates its capital expenditure on $\mathrm{ABC}$ will reach around $\$ 70$ billion over the 20 -year life of its contract while IOC promised to invest $\$ 88$ billion through 2041 to boost production in ABC.

There are concerns related this appointment, first one regarding NOC capabilities in handling an over mature stage oil block. The closest evidence is one that happen in Siak Block, ABC's neighboring block, which acquired by Pertamina Hulu Energi (PHE), as one of NOC subsidiaries in upstream sector from IOC in 2014. Siak block consisted mainly 3 (three) oil fields including Batang field, one which applied the Prefeasibility study of stream flood technology. The production is still below its initial target when handed over from IOC.

Another interesting concern on how NOC recently acquired Mahakam Block in East Kalimantan from Total E\&P Indonesie in the early 2018 but still hardly catching up on the expected hydrocarbon production target. Peeking on the business aspect, NOC current financial capability is not exactly in the state-of-theart level as well.

Latest concern is regarding fiscal policy term imposed in ABC; Gross-split scheme. For XYZ field, it is agreed that NOC will take $70 \%$ for oil and $70 \%$ for natural gas while for non XYZ Field, NOC will take $61 \%$ for oil and $66 \%$ for natural gas. The GOI believes that the latter scheme will provide a better rate of return to the contractor, but recent study show that gross split PSC is not more superior fiscal regime than standard net PSC. Although the gross split PSC gives the better structure of progressivity and simple administration, the exceed risk for contractors regarding the profitability make the sharing risk is not balance.

\section{METHOD}

The business issue is to find the optimum investment strategy of XYZ field under Indonesia's Gross Split PSC. In order to have optimum investment strategy it will need to analyze the external environment and internal environment. From internal and external analysis, business strategy can be developed and by 
performing investment analysis thru economic feasibility, we can arrive to the conclusion and recommendation.

The external environment will be evaluated based on data from general environment and industry environment. The general environment will analyze various aspect such as: demographic of Indonesia, economic contribution, political/legal to oil and gas industry, sociocultural, technological, global environment, as well as physical environment. While industry environment analysis will use Porter's Five Force concept. The internal environment will be evaluated using SWOT \& TOWS of ABC Block PSC. By having qualitative analysis from internal and external environment, it is expected that we will have right business strategy analysis for next operator to operate in the heavy oil field under ABC Block PSC.

After having the business strategy, the other aspect that author will analyze is the quantitative assessment of economic feasibility of the investment. The economic feasibility will use capital budget analysis and sensitivity analysis. With various scenarios applied, it is expected that we will have optimum investment scenario based on quantitative analysis. After completing the quantitative and qualitative analysis, we combine the result and having a conclusion and recommendation to the investment of heavy oil field under gross split PSC.

\section{RESULT AND DISCUSSION}

From the external environment analysis, some segment has positive impact to the industry, such as demographic segment, economic, technological, and global segments. The condition of Indonesia as 4th largest population in the world and the outlook of economic of Indonesia made Indonesia as an attractive place for investment. The political/legal segment has negative impact as a result of complex regulation. This condition made the industries looks unappealing. It is also major reason of declining oil production for last two decades. The sociocultural and physical environment segments have medium-positive impact, as it can be controlled based on the business activities, and can be implemented with good project planning. Analysis of the five forces allow the firm to determine the industry's attractiveness in terms of the potential to earn average or above average returns. In general, the stronger the competitive forces, the lower the potential for firms to generate profits by implementing their strategies. Based on five forces analysis that can be seen in Figure 1 below, we can conclude that upstream oil and gas industry in Indonesia is an attractive industry that allow firm to earn average or even above-average returns by implementing its strategies. 


\section{FIGURE 1 \\ SUMMARY OF FIVE FORCES ANALYSIS}

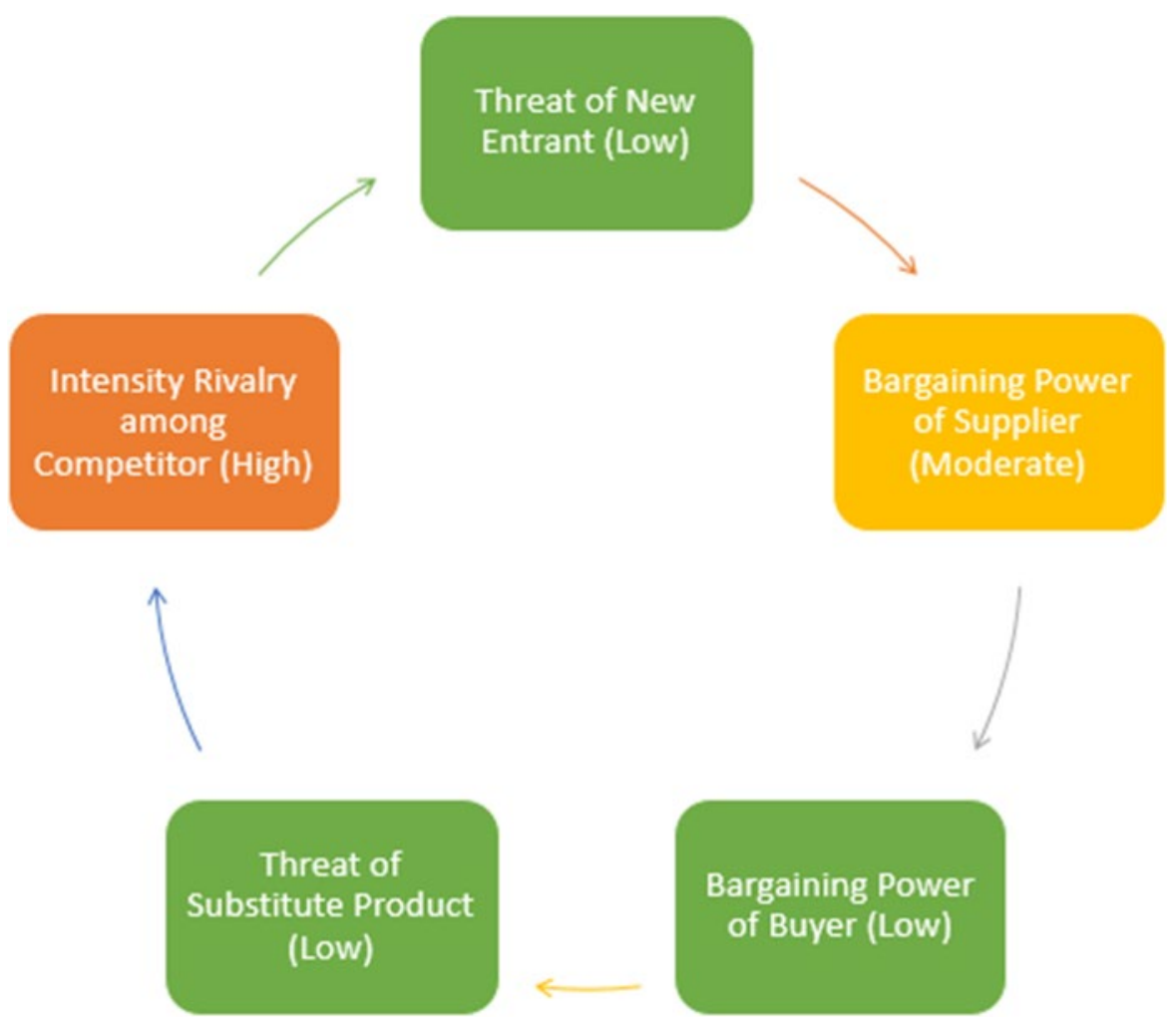

Next important analysis to understand the business issue is internal analysis of ABC Block. The internal analysis will use SWOT analysis as it is a powerful tool to identify and analyze internal strength and weakness and external opportunities and threat. Summary of SWOT analysis can be seen in Table 1.

TABLE 1

SUMMARY OF SWOT ANALYSIS

\begin{tabular}{|ll|}
\hline \multicolumn{1}{|c|}{ Strengths $(+)$} & \multicolumn{1}{c|}{ Weaknesses $(-)$} \\
$\begin{array}{l}\text { Low lifting cost } \\
\text { Established infrastructures } \\
\text { High skill and talented resources or employee }\end{array}$ & $\begin{array}{l}\text { Mature Field } \\
\text { Decline in production } \\
\text { Aging facilities }\end{array}$ \\
\hline \multicolumn{1}{|c|}{ Opportunities $(+)$} & \multicolumn{1}{c|}{ Threats $(-)$} \\
\hline $\begin{array}{l}\text { Area for new POD } \\
\text { High demand for oil } \\
\text { New advance technology for tertiary recovery }\end{array}$ & $\begin{array}{l}\text { Oil price fluctuation } \\
\text { Unexpected regulation from government }\end{array}$ \\
\hline
\end{tabular}

In order to evaluate investment analysis in ABC Block, it is needed to develop alternatives to be assess. As common practices in the industry, the investment will involving new drilling programs, either to maintain production level or even to boost the production. Specific to XYZ field, the drilling programs can be executed in current developed area and in new area. Based on that condition, there are three alternatives to be assess. 
First alternative (Alternative-1) is only executing new drilling program in existing area of XYZ field. This program typically called as a Horizontal Well (HW) program due to the drilling direction will be in horizontal direction instead of vertical direction. Alternative-1 will generate low additional production into Baseline with low investment cost. Second alternative (Alternative-2) is by developing new area in XYZ field. As informed earlier that there is opportunity to develop new area within XYZ field. Alternative-2 is expected to add production to estimate $45 \mathrm{MBOPD}$ at its peak production as can be seen in production profile chart later. Last alternative (Alternative-3) is to combine both previous alternatives. Last alternative will have maximum additional production as well as maximum investment cost.

\section{Model Assumption}

The forecast production with current wells is about 60 MBOPD in 2021. This condition will be a 'Baseline' into the production profile. To evaluate investment analysis in ABC Block, there are three alternatives to be assess and can be seen in Table 2 below.

TABLE 2

MODEL ASSUMPTION COMPARISON

\begin{tabular}{|lccc|} 
& $\begin{array}{c}\text { Alt 1- Current Area } \\
\text { Development } \\
\text { Program }\end{array}$ & $\begin{array}{c}\text { Alt 2- New Area } \\
\text { Development Program }\end{array}$ & $\begin{array}{c}\text { Alt 3-Combination } \\
\text { Development } \\
\text { Program }\end{array}$ \\
\hline $\begin{array}{l}\text { Additional } \\
\text { Production }\end{array}$ & Low & Medium & High \\
\hline Capex & Low & Medium & High \\
\hline New Well Drilled & 3/month & $5 /$ month & $8 /$ month \\
\hline
\end{tabular}

There are model assumption used in this research:

- Split Calculation is calculated based on condition of XYZ Field. In summary, total contractor split for XYZ field is $70 \%$.

- Oil price will be based on approach of USD 65 per barrel, flat along the 20 years PSC contract life. This is based on judgment that historically that oil price is flat.

- Effective tax rate for corporate is $44 \%$ from internal sources.

- Investment analysis is calculated during PSC life for 20 years.

- Weighted Average Cost of Capital will be $10 \%$ as a hurdle rate

- Depreciation method for tangible well is 5-years with $25 \%$ per year depreciation while for other asset will be 7-years.

\section{Alternative-1 - Current Area Development Program \\ Production Profile of Alternative-1}

Alternative-1 assumed that there is no development on new area of XYZ field, hence additional production will be based on HW drilling program on current area. The program will start immediately in Q3-2021 and ended in 2036 due to minimizing undepreciated cost from the program and will drill 3 new wells each month. The oil production is start with 62 thousand BOPD in 2021 and followed by an exponential depletion rate of $15 \%$ over the lifetime of the PSC until it reaches 22 thousand BOPD in 2041. Figure 2 below show the production profile for Alternative-1. 
FIGURE 2

\section{PRODUCTION PROFILE FOR ALTERNATIVE-1}

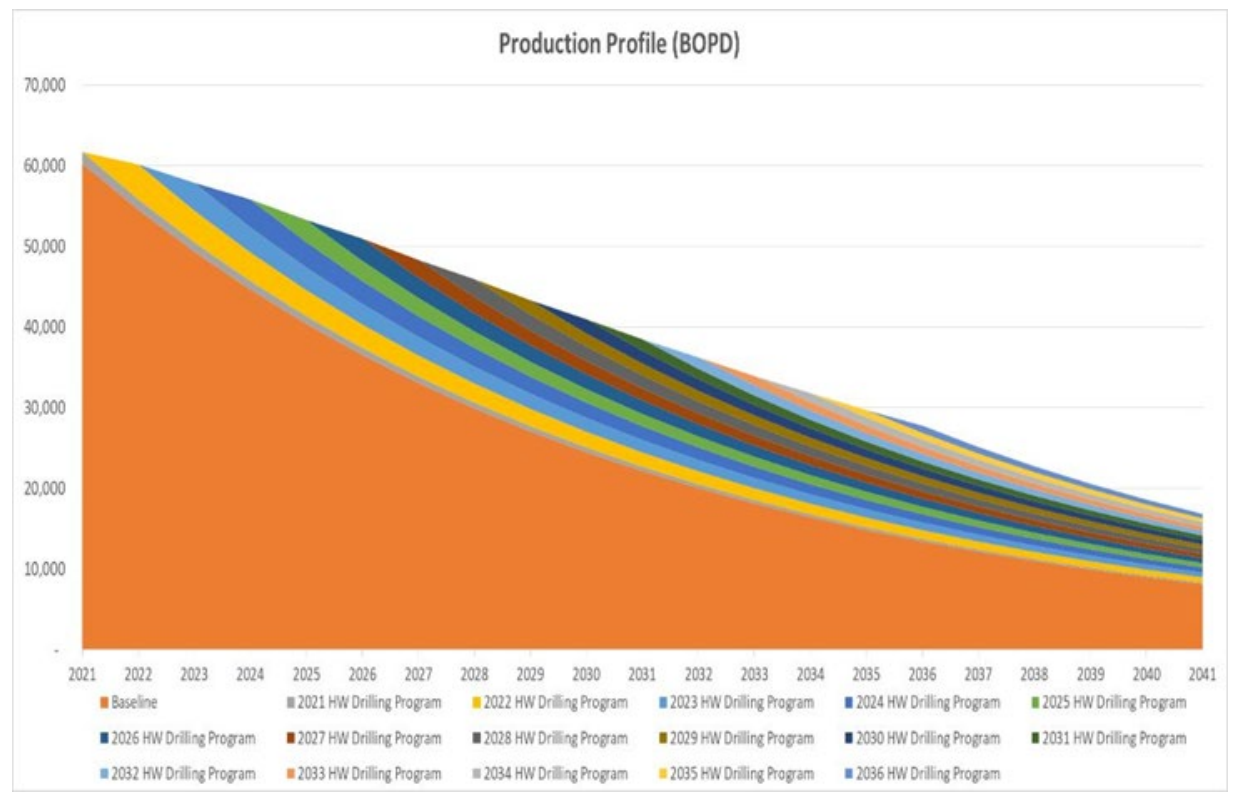

Capital Expenditure of Alternative-1

Total Capital Expenditure for Alternative-1 is USD 1,268.9 million comprise of tangible drilling well of USD 232.9 million and USD 663.2 million of intangible wells. This number is representing 552 new drilling wells. There is also CAPEX about USD 372.8 million to construct pipeline from wellhead to nearest production line and other production facilities that will support the program. The complete profile of CAPEX for alternative-1 can be seen in Figure 2 below.

\section{FIGURE 3}

\section{CAPEX PROFILE FOR ALTERNATIVE-1}

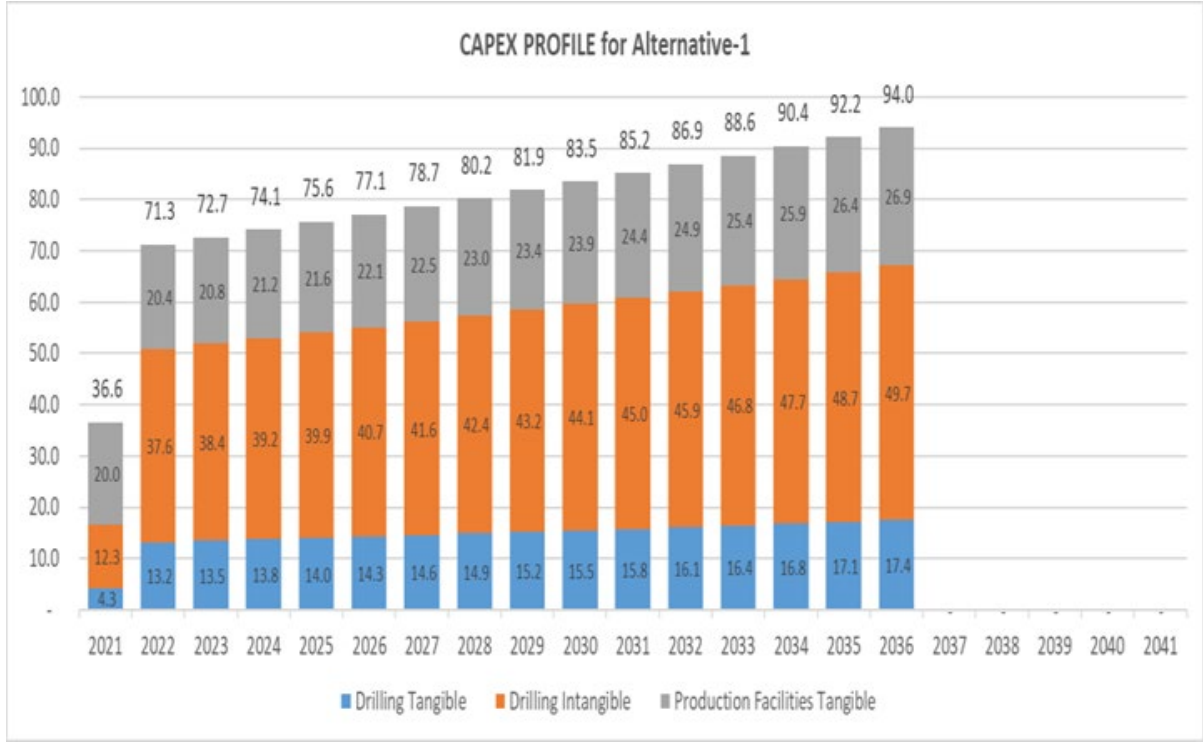


Operating Expenditure of Alternative-1

The operating expenditure of Alternative- 1 can be seen in Figure 3 below. The profile of variable cost is aligned with profile of oil lifting. In 2021, it is only 4-month operation hence total lifting is about 9.1million-barrel oil with USD 114 million variable cost. The variable cost in 2022 is about USD 295 million to handle 23.2-million-barrel oil. Then variable cost is decline as production decline until it reaches USD 89.2 million to process 4.8 -million-barrel oil in 2041. The fixed cost is increased each year as an effect of inflation. The other cost is consisting of G\&A cost, overhead cost and intangible well cost. This cost is increasing each year but decline in 2037 as the HW program stopped in 2036.

\section{FIGURE 4}

\section{OPEX PROFILE FOR ALTERNATIVE-1}

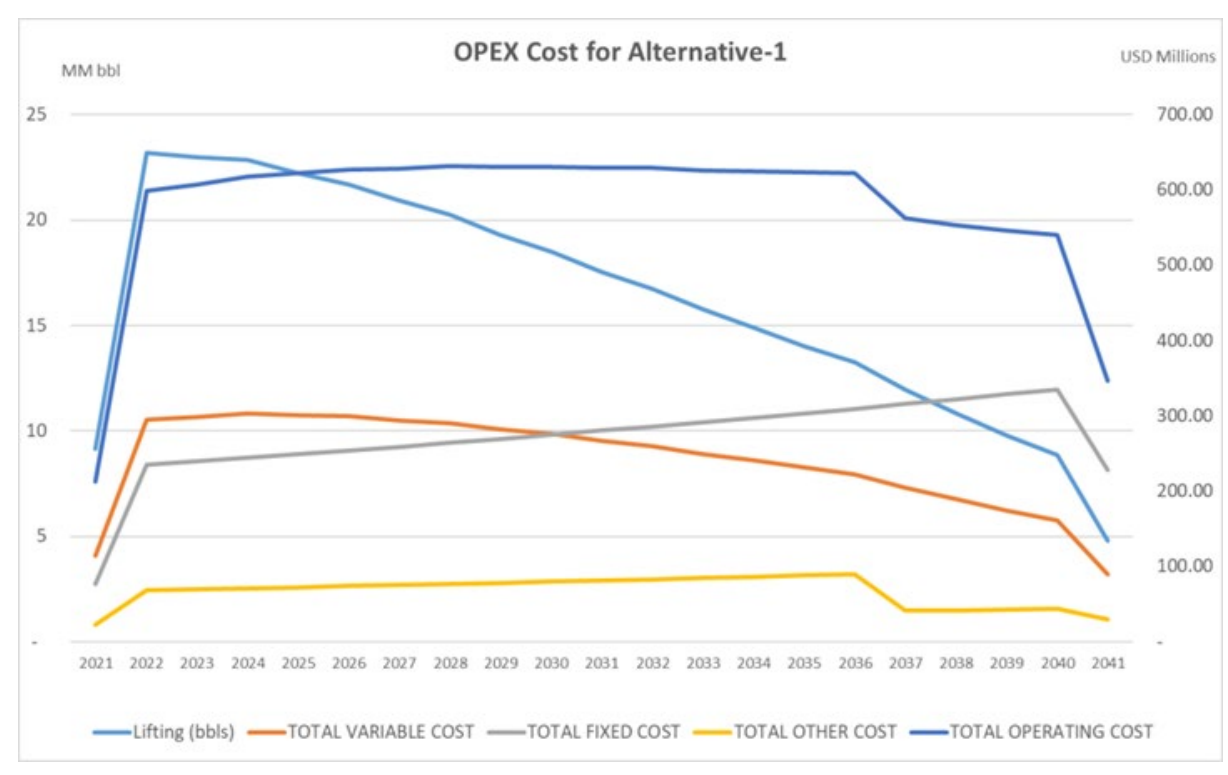

Contractor Cash Flow and NPV of Alternative-1

Based on Gross Split PSC Mechanism, the alternative-1 will generate total production of 339.35million-barrel oil equivalent. Figure 5 below show selected information regarding result for Alternative-1 such as gross revenue profile, contractor's share profile, contractor's take, and cash flow profile. In 2021, due to NOC is starting operation in end of August, it only receives $1 / 3$ of yearly production. Gross Revenue in 2021 is USD594 million with contractor's share USD 415.84 million or $70 \%$ as split calculation. This share then deducted by OPEX, depreciation, ASR funding and tax to become contractor's take of USD 83.14 million. The cash flow schedule in Figure 5 below resulting contractor's NPV of USD 504.7 million. Based on capital budgeting calculation, the IRR of Alternative- 1 is equal with $10.4 \%$. 


\title{
FIGURE 5 \\ GROSS REVENUE, CONTRACTOR'S SHARE, TAKE AND CASH FLOW OF ALTERNATIVE-1
}

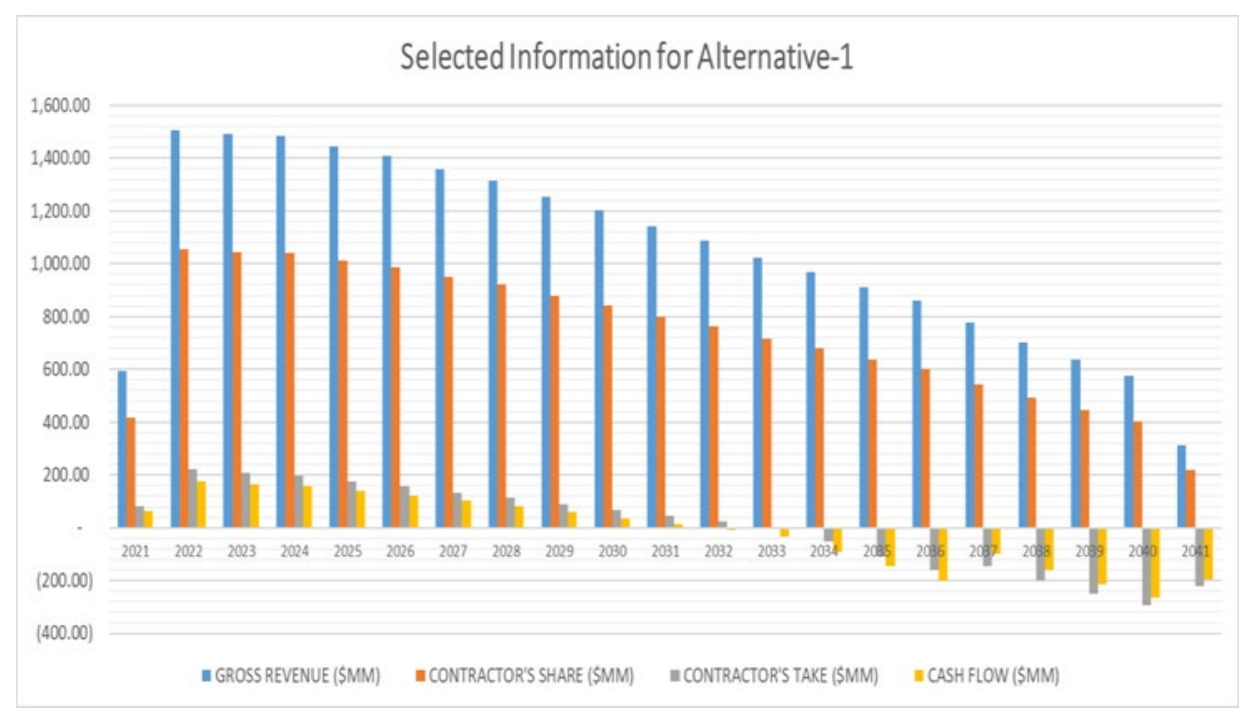

\begin{abstract}
Alternative-2 - New Area Development Program
Production Profile of Alternative-2

Alternative-2 assumed that NOC will develop new area in XYZ Field. The development in new area hence gives NOC more additional barrel to be lifting from reservoir. Due to the project is more complicated than HW Project in Alternative-1, The New Area development program will start in 2022 for about 8 years. The program will drill 5 new wells each month. The oil production is start with baseline number of 60 thousand BOPD in 2021 and planned to increase each year until it reaches its peak production of 71 thousand BOPD in 2029 and forecasted to decline until 27 thousand BOPD in 2041. Figure 6 below show the production profile for Alternative-2.
\end{abstract}

FIGURE 6

\section{PRODUCTION PROFILE FOR ALTERNATIVE-2}

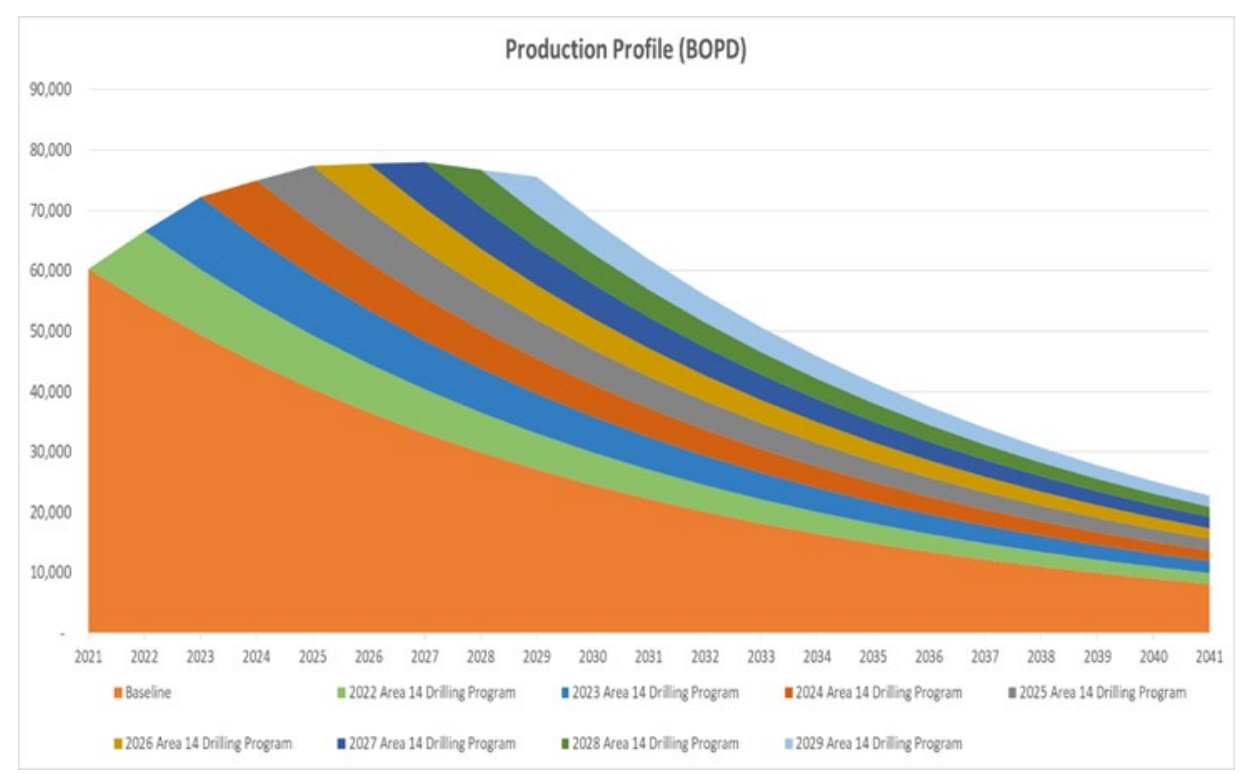




\section{Capital Expenditure of Alternative-2}

Total Capital Expenditure for Alternative-2 is USD 1,533.7 million comprise of tangible drilling well of USD 189.1 million and USD 538.4 million of intangible wells. This number is lower than total drilling cost in Alternative-1 due to it representing lower drilling wells of 480. Despite that, Alternative-2 has a higher Capital Expenditure to construct production facilities. Due to the program is to open new area, it is expected that NOC will construct production facilities such as Gathering Station, Test Station and other facilities to support the program. Total CAPEX for production facilities is USD 806.2 million. The complete profile of CAPEX for alternative-1 can be seen in Figure 7 below.

FIGURE 7

CAPEX PROFILE FOR ALTERNATIVE-2

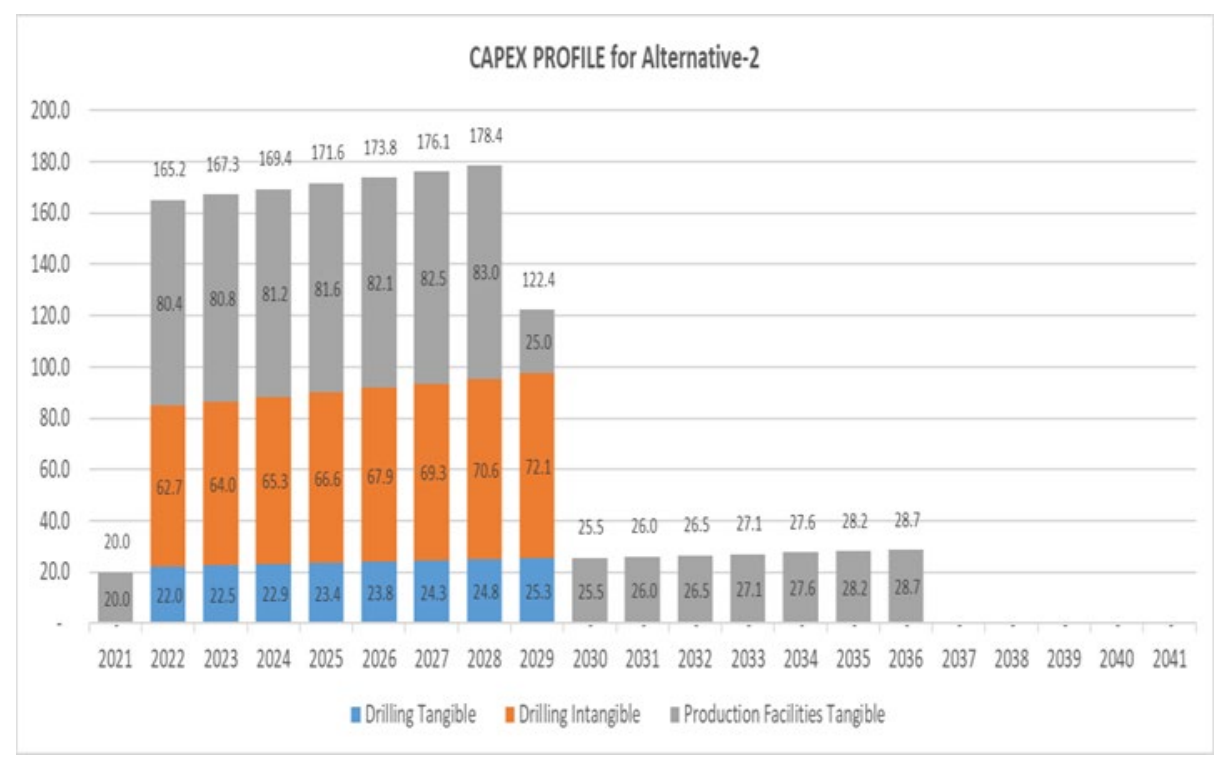

\section{Operating Expenditure of Alternative-2}

The operating expenditure of Alternative- 2 can be seen in Figure 8 below. The profile of variable cost is aligned with profile of oil lifting. In 2021, it is only 4-month operation hence total lifting is about 8.8million-barrel oil with USD 110 million variable cost. The variable cost in 2022 is about USD 306 million to handle 23.9-million-barrel oil. Then variable cost is decline as production decline until it reaches USD 88.1 million to process 4.7-million-barrel oil in 2041. The fixed cost is increased each year as an effect of inflation. The other cost is consisting of G\&A cost, overhead cost and intangible well cost. This cost is increasing each year but decline in 2030 as the new area development program stopped in 2029. 
FIGURE 8

OPEX PROFILE FOR ALTERNATIVE-2

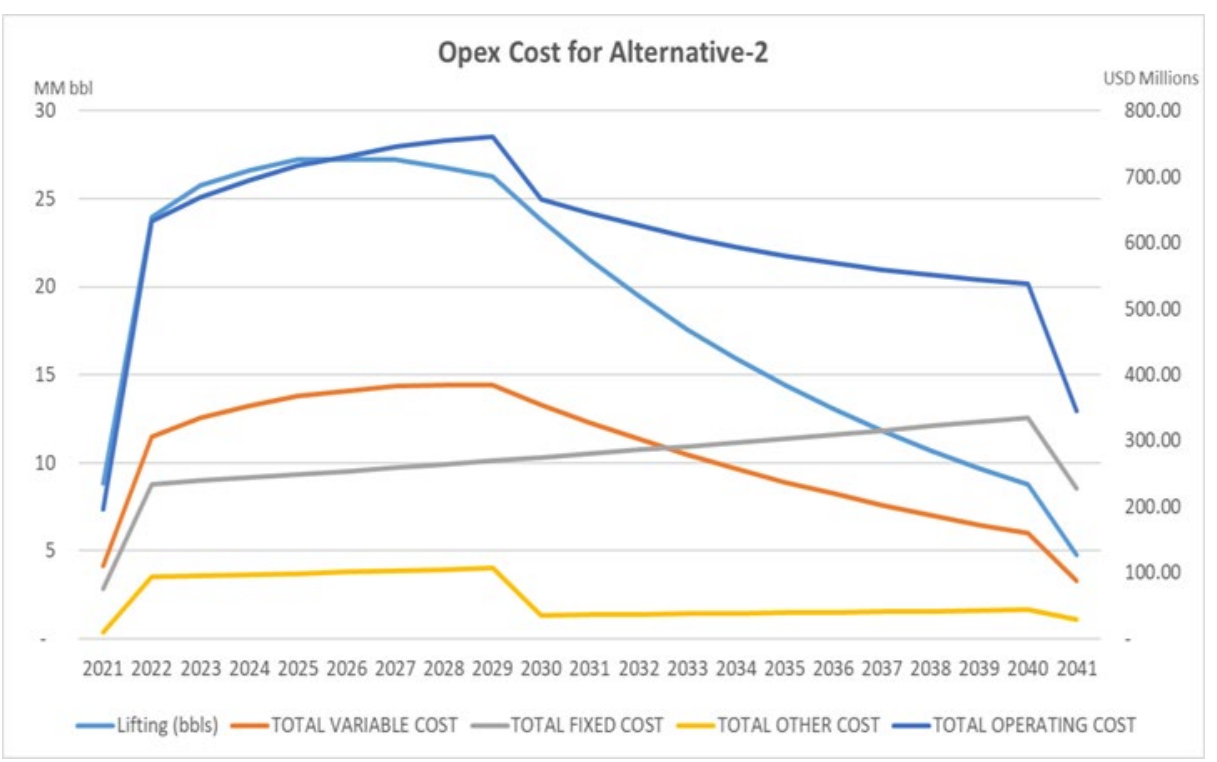

Contractor Cash Flow and NPV of Alternative-2

Based on Gross Split PSC Mechanism, the alternative-2 will generate total production of 391.39million-barrel oil equivalent. Figure 9 below show selected information regarding result for Alternative-2 such as gross revenue profile, contractor's share profile, contractor's take, and cash flow profile. In 2021, due to NOC is starting operation in end of August, it only receives $1 / 3$ of yearly production. Gross Revenue in 2021 is USD572 million (lower than Alternative-1 due to no drilling program) with contractor's share USD 400.69 million or $70 \%$ as split calculation. This share then deducted by OPEX, depreciation, ASR funding and tax to become contractor's take of USD 81.07 million. The cash flow schedule in Figure 9 below resulting contractor's NPV of USD 795.8 million. Based on capital budgeting calculation, the IRR of Alternative- 2 is equal with $15.0 \%$.

FIGURE 9

\section{GROSS REVENUE, CONTRACTOR'S SHARE, TAKE AND CASH FLOW OF ALTERNATIVE-2}

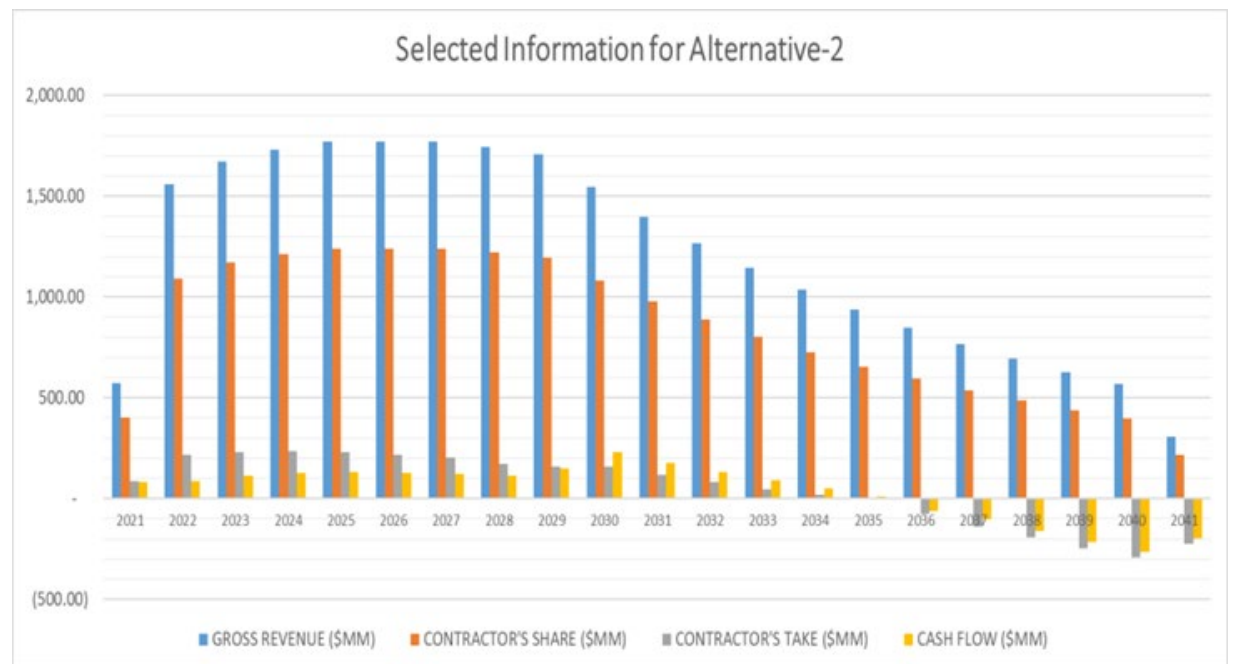




\section{Alternative-3 - Combination Development Program}

Production Profile of Alternative-3

Alternative- 3 as a combination between Alternative- 1 and Alternative- 2 has the highest production profile among the alternatives. The oil production is start with 62 thousand BOPD in 2021, increase each year as the new area development progressing until 2029 and then forecasted to decline until it reaches 35 thousand BOPD in 2041. Figure 10 below show the production profile for Alternative-3.

\section{FIGURE 10 \\ PRODUCTION PROFILE FOR ALTERNATIVE-2}

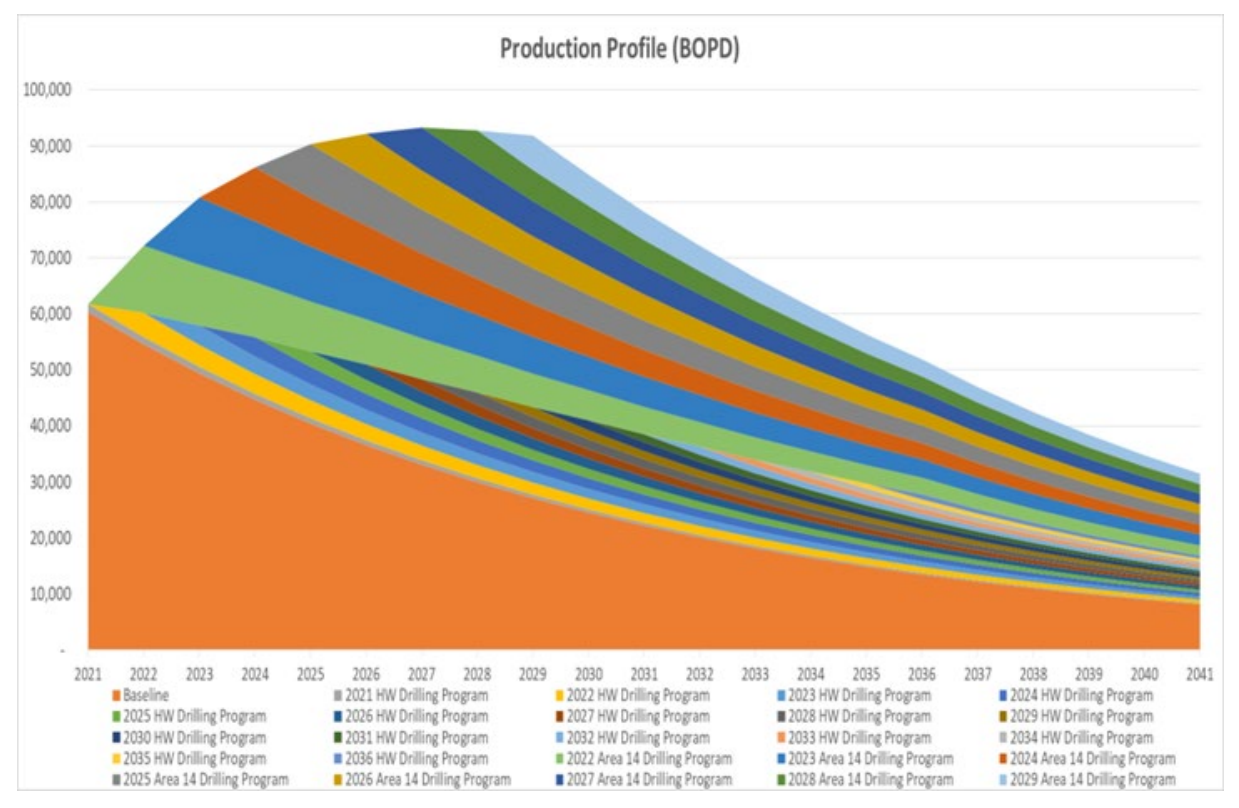

Capital Expenditure of Alternative-3

Total Capital Expenditure for Alternative-3 is USD 2,429.9 million comprise of tangible drilling well of USD 422.0 million and USD 1,201.6 million of intangible wells. This number is representing 1,002 new drilling wells. Since this Alternative is adopt Alternative-2, hence the CAPEX for production facilities is similar with Alternative-2 of USD 806.2 million to construct pipeline from wellhead to nearest production line and other production facilities that will support both programs. The complete profile of CAPEX for alternative- 1 can be seen in Figure 11 below. 
FIGURE 11

\section{CAPEX PROFILE FOR ALTERNATIVE-3}

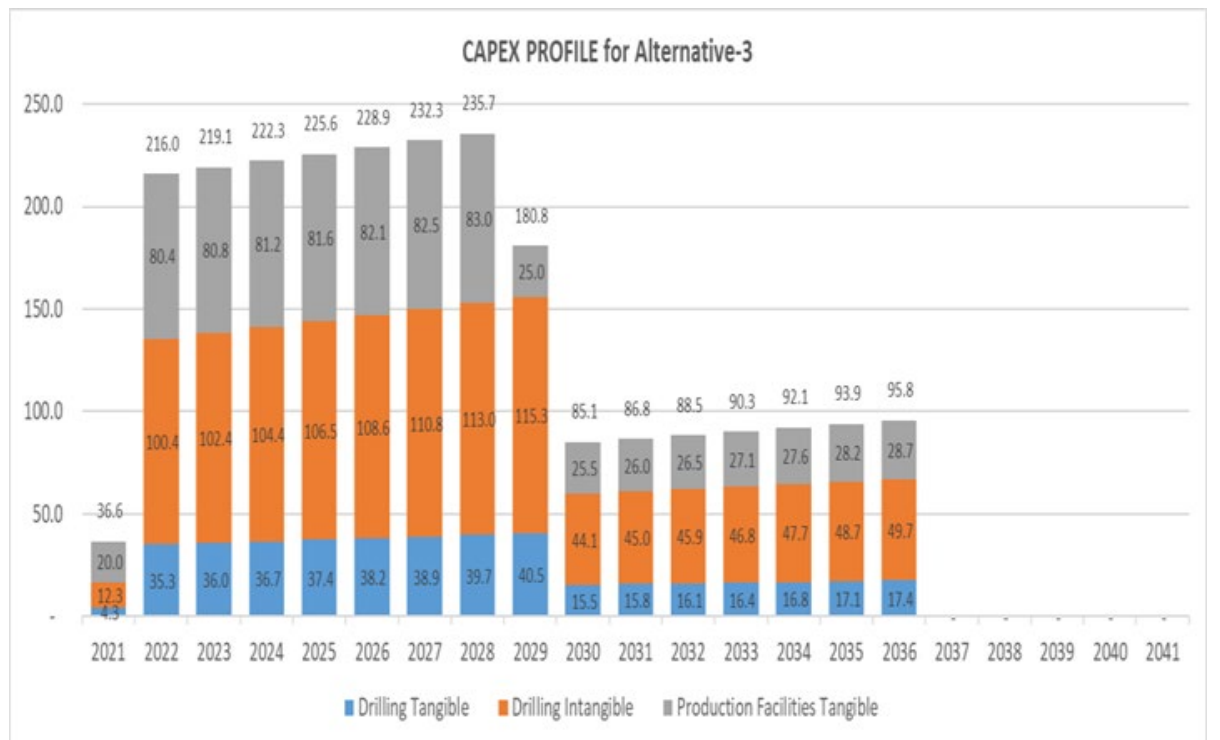

\section{Operating Expenditure of Alternative-3}

The operating expenditure of Alternative- 3 can be seen in Figure 12 below. The profile of variable cost is aligned with profile of oil lifting. In 2021, it is only 4-month operation hence total lifting is about 9.1million-barrel oil with USD 114 million variable cost. The variable cost in 2022 is about USD 346.9 million to handle 27.2-million-barrel oil. Then variable cost is decline as production decline until it reaches USD 144.1 million to process 7.8-million-barrel oil in 2041. The fixed cost is increased each year as an effect of inflation. The other cost is consisting of G\&A cost, overhead cost and intangible well cost. This cost is increasing each year but decline in 2030 as new area stopped in 2029 and then decline again in 2037 as the HW program stopped in 2036.

FIGURE 12

\section{OPEX PROFILE FOR ALTERNATIVE-3}

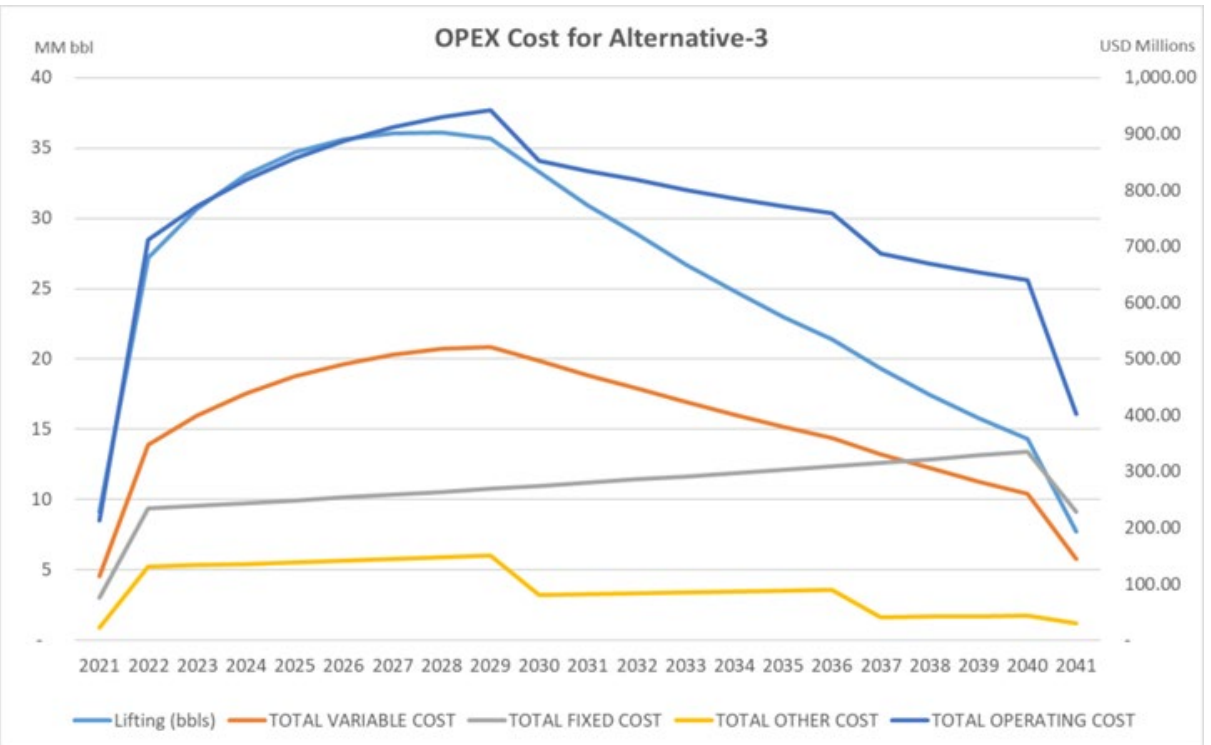


Contractor Cash Flow and NPV of Alternative-3

Based on Gross Split PSC Mechanism, the alternative-3 will generate total production of 542.01million-barrel oil equivalent. Figure 13 below show selected information regarding result for Alternative-3 such as gross revenue profile, contractor's share profile, contractor's take, and cash flow profile. In 2021, due to NOC is starting operation in end of August, it only receives $1 / 3$ of yearly production. Gross Revenue in 2021 is USD 594 million (similar with Alternative-1) with contractor's share USD 416 million or 70\% as split calculation. This share then deducted by OPEX, depreciation, ASR funding and tax to become contractor's take of USD 81.56 million. The cash flow schedule in Figure 13 below resulting contractor's NPV of USD 1,386.0 million. Based on capital budgeting calculation, the IRR of Alternative-2 is equal with $31.0 \%$.

\section{FIGURE 13 \\ GROSS REVENUE, CONTRACTOR'S SHARE, TAKE AND CASH FLOW FOR ALTERNATIVE-3}

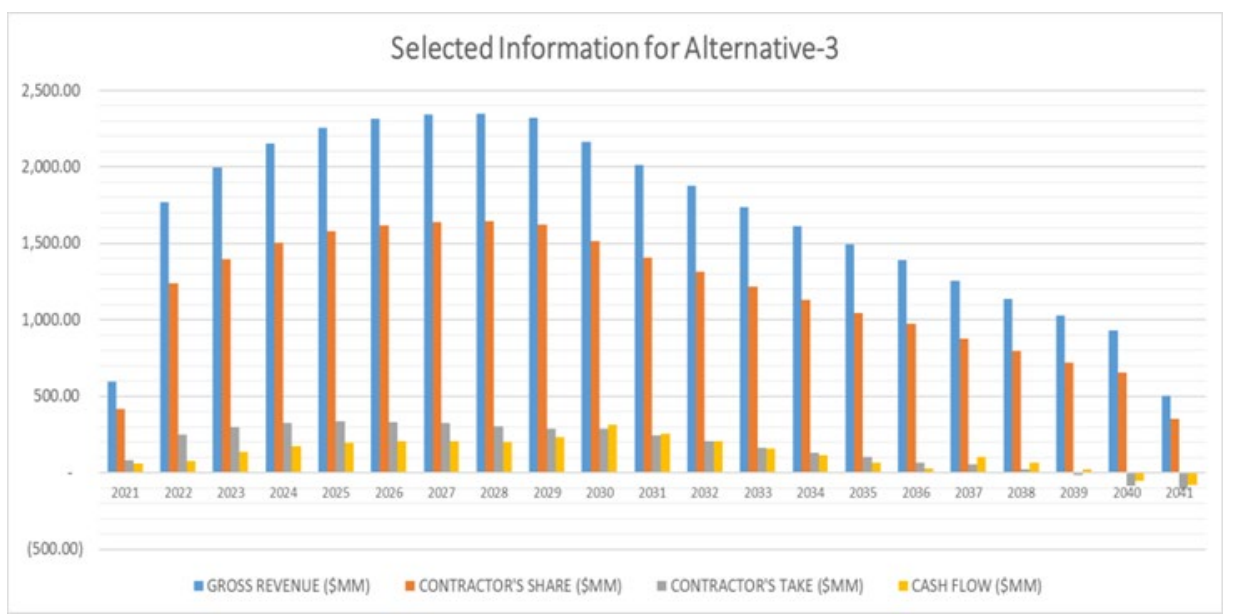

\section{Sensitivity and Decision Analysis}

Sensitivity analysis is conducted to know how much the parameter of investment result will change due to changes on some aspect of the data. The parameter that will be analyze in sensitivity analysis are Oil Production, Oil Price, Oil Depletion Rate, and WACC Hurdle rate. The range of sensitivity are from $-20 \%$ to $+20 \%$ with an increase of every $10 \%$. Figure 14 below show sensitivity analysis for Alternative-3.

\section{FIGURE 14 SENSITIVITY ANALYSIS FOR ALTERNATIVE-3}

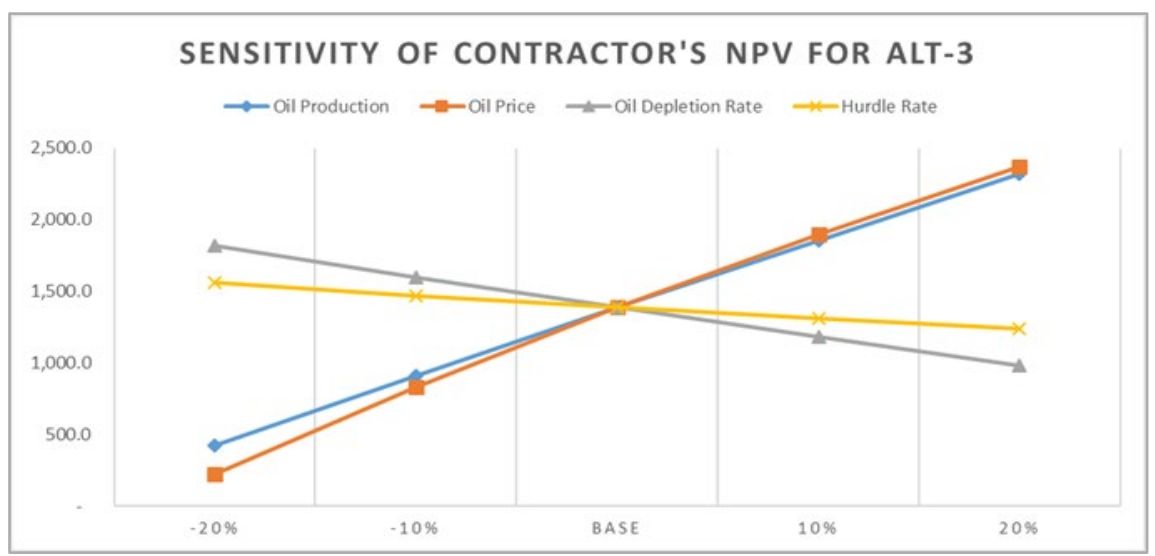


Overall summaries of the sensitivity analysis are:

- For Alternative-1, NPV become negative when oil production or oil price is decrease more than $10 \%$ from baseline while increase in oil depletion rate up to $20 \%$ still giving positive NPV.

- For alternative 2, oil price is more sensitive than oil production and it is giving negative NPV when oil price decreases more than $17 \%$. Increase in depletion rate up to $20 \%$ still giving positive NPV.

- For alternative 3, event ought oil price or production decrease to $20 \%$ from baseline, it still gives positive NPV.

From various number of results of NPV for alternative-1 to Alternative-3, we can calculate Coefficient of Variance that represent the risk of each alternative. From Table 3 below, Alternative- 3 is having smallest Coefficient of Variant (CV) value, those it can be concluded that Alternative- 3 is the best alternative to be selected.

TABLE 3

\section{SUMMARY OF ECONOMIC RESULT}

\begin{tabular}{|l|c|c|c|}
\hline & $\mathrm{E}(\mathrm{r})$ & STDEV & CV \\
\hline Alternative-1 & 504.7 & 457.9 & 0.91 \\
\hline Alternative-2 & 795.8 & 489.7 & 0.62 \\
\hline Alternative-3 & $1,386.0$ & 592.6 & 0.43 \\
\hline
\end{tabular}

\section{CONCLUSION}

From external and internal analysis of ABC Block and XYZ Field using SWOT and TOWS analysis, there are five strategies that can be implemented: (1) Long-term investment planning; (2) Facilities Rationalization Program; (3) close coordination with stakeholders; (4) improve production level; and (5) maintain baseline production.

From those strategies, then it can be concluded that investment strategies that should be executed in $X Y Z$ field cannot be in short-term or medium term. The investment option must consider the production of XYZ field.

The results of economic analysis show that those three alternatives are giving positive NPV and IRR that higher than hurdle rate with detail: Alternative-1 has NPV of 504.7 million dollar and 10.4\% IRR, Alternative-2 has NPV of 795.8 million dollar and 15.0\% IRR, and Alternative-3 has NPV pf 1,386.0 million dollar and $31.0 \%$ IRR. Alternative- 3 as a combination from Alternative- 1 and Alternative- 2 is having highest NPV and IRR values.

Oil price and oil production have positive correlation to NPV \& IRR while oil depletion rate has negative correlation. For alternative-3, minimum NPV is happen when oil price drop $20 \%$ from baseline $(80 \% * \$ 65 / \mathrm{bbl}=\$ 52 / \mathrm{bbl})$ to around $\$ 224.3 \mathrm{MM}$ with IRR of $10.8 \%$ (close to hurdle rate of $10 \%)$. While Hurdle rate is less sensitive in three alternatives. Decrease or increase in hurdle rate up to $20 \%$ did not give significant impact to the NPV or IRR.

Based on further analysis using Coefficient of Variant (CV) method, it is shown that Alternative-3 has lowest $\mathrm{CV}$ value that other alternatives. This result is consistent with previous finding that Alternative-3 is the best alternative among the others.

The following are author's recommendations for maintaining or improving the economic feasibilities of the XYZ block: Alternative-3 is the most feasible of the three options, hence NOC should implement it. The development of a new area in the XYZ field necessitates a large sum of capital. Despite the fact that the hurdle rate has a minor impact on the field's profitability, NOC must obtain cash, either in the form of 
debt or equity. Since XYZ is a mature field that might be impact to higher depletion rate than it is predicted, NOC must maintain its operating expense in order to balance the rate of depletion or decline in production.

\section{REFERENCES}

Asmarini, W. (2018, July 31). Indonesia's Pertamina to take over Chevron's Rokan block in 2021. Reuters. Retrieved January 28, 2019, from https:/www.reuters.com/article/us-chevron-indonesiarokan/indonesias-pertamina-to-take-over-chevrons-rokan-block-in-2021-idUSKBN1 KL2B6

Gitman, L.J., \& Zutter, C.J. (2012). Principles of Managerial Finance (13th ed.). New York: Prentice Hall.

Halim, I. (2018, August 1). Indonesia's Rokan Block Handover: A Purely Technical and Business Consideration or A Mere Political Populist Agenda? Medium. Retrieved January, 28, 2019, from https://medium.com/@ismaelhalim/unique-perspective-on-indonesias-rokan-block-handover-topertamina-a-purely-technical-and-9da63bce1 fe2

Hitt, M.A., Ireland, R.D., \& Hoskisson, R.E. (2016). Strategic Management: Competitiveness \& Globalization: Concepts and Cases (12th ed.). Boston: Cengage Learning.

Lubiantara, B. (2012). Ekonomi Migas: Tinjauan Aspek Komersial Kontrak Migas. Jakarta: PT. Gramedia Widiasarana Indonesia.

Maulia, E. (2018, August 1). Pertamina wins bid to take major Indonesia oil block from Chevron. Asia Nikkei. Retrieved January 28, 2019, from https://asia.nikkei.com/Business/BusinessDeals/Pertamina-wins-bid-to-take-major-Indonesia-oil-block-from-ChevronPwC

PwC Indonesia. (2012). Oil and Gas Indonesia: Investment and Taxation Guide.

PwC Indonesia. (2018). Oil and Gas Indonesia: Investment and Taxation Guide. 